\title{
ATELLÊE
}

\section{De la invisibilidad al liderazgo comunitario: las mujeres cortamate del Valle del Patía}

\author{
Da invisibilidade à liderança comunitária: \\ as mulheres cortamate do Vale de Patia \\ From invisibility to community leadership: \\ Cortamate women from Patia Valley
}

Luis Antonio Rosas Guevara

Universidad del Cauca - Colombia

luisrosas@ unicauca.edu.co

\begin{abstract}
Resumen
Con este artículo se pretende visibilizar la importancia de los saberes y las tradiciones ancestrales de las mujeres cortamate del Valle del Patía, en tanto estos constituyen un acto de resistencia a las imposiciones de las economías globales, y objeto de la memoria histórica de los pueblos afrodescendientes de esta región de Colombia. La capacidad organizativa y comunitaria promovida por este grupo de mujeres afropatianas se soporta en sus prácticas locales y territoriales como un largo proceso de resignificación de su territorio, sus tradiciones, su lugar como "mujeres negras" y la alternativa a la pobreza que azota a sus comunidades. Reconocer y dar lugar académico a esta memoria histórica de las mujeres cortamate del Valle del Patía permite reconstruir el papel político, social y cultural que ellas han cumplido en su región, y permite otorgar voz a quienes durante mucho tiempo han sido las invisibles del Patía. En ese sentido este trabajo retoma de viva voz, los testimonios y reflexiones de algunas de las cortamate, como un ejercicio para acentuar el análisis sobre sus luchas comunitarias y culturales.
\end{abstract}

Palabras claves: Mujeres afropatianas, territorio, economía local, etnodesarrollo. 


\begin{abstract}
Resumo
Com este artigo pretende-se visibilizar a importancia dos saberes e as tradicões ancestrais das mulheres cortamate do Valle do Patía, uma vez que estes constituem um ato de resistência às imposições das economias globais, e objeto da memória histórica dos povos afrodescendentes desta região da Colômbia. A capacidade organizativa e comunitária promovida por este grupo de mulheres afropatianas se apoia em suas práticas locais e territoriales como um longo processo de redefinição do seu território, suas tradições, seu lugar como "mulheres negras" e a alternativa à pobreza que assola suas comunidades. Reconhecer e dar lugar académico a essa memória histórica das mulheres cortamate do Valle Do Patía permite reconstruir o papel político, social e cultural que elas têm cumprido em sua região, e permite conceder voz a quem durante muito tempo têm sido as invisíveis do Patía. Nesse sentido, este trabalho retoma de voz alta, os depoimentos e reflexões de algumas das cortamate, como exercício para enfatizar a análise sobre suas lutas comunitárias e culturais.
\end{abstract}

Palavras-chave: Mulheres afropatianas, território, economia local, etnodesenvolvimento.

\begin{abstract}
This article aims to make visible the importance of the ancestral traditions and knowledge of cortamate women from Patia Valley, since they constitute an act of resistance to the impositions of the World Economy, and the subject of the historical memory of African descent communities in this region of Colombia. The organizational and community capacity promoted by cortamate women is supported in their local and regional practices as a long process of redefinition of their territory, traditions, and place as "black women". It is also seen as an alternative to poverty plaguing their communities. The fact of recognizing and giving the historical memory of this group of women a place in the academic field permits the reconstruction of their political, social, and cultural role in their region; and it helps to give voice to those who have been invisible for a long time in history of Patia. This way, this paper draws out testimonies and reflections of some of the cortamates, as an exercise to emphasize the analysis of their community and cultural struggles.
\end{abstract}

Keyworks: Cortamate Women. Territory. Local Economies. Ethnodevelopment. 
Que las voces de las mujeres nunca se callen, que se escuchen siempre!!!.

\section{LAS VOCES DE LAS MUJERES SON UN} ALABAO A LA VIDA..

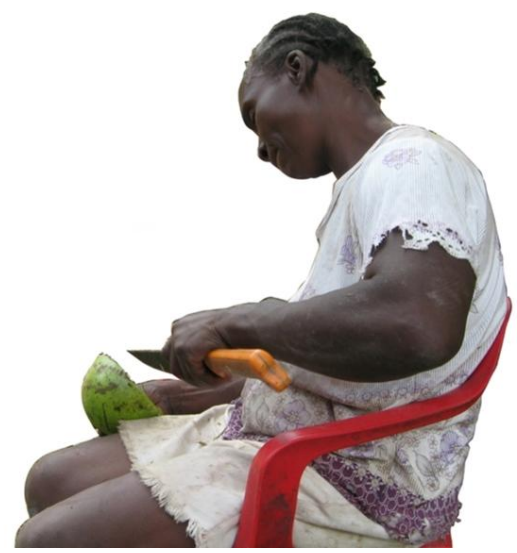

Figura 1 - Mujer cortamate de la vereda La Ventica. Municipio del Patía (CaucaColombia). Foto: Luis Antonio Rosas

Las cortamates son parte del pueblo afrocolombiano que durante vetustos tiempos se estableció en la región del Valle del Patía denominado comúnmente por los geógrafos la "fosa del Patía" o "cuenca patiana". Estas mujeres de descendencia africana, tradicionalmente han dedicado su vida a la práctica de cortar los frutos del árbol de totumo[1] para su subsistencia. El totumo es un arbusto pequeño que ellas suelen llamar el "árbol mágico del valle del Patía", por cuanto se ha constituido como la fuente esencial de sostenimiento de sus familias. Las mujeres que realizan este oficio en el valle del Patía son reconocidas por la comunidad como "mujeres cortamates".

Zuluaga, plantea en relación con el surgimiento de la explotación del puro, lo siguiente:

[...] Recabando en sus tradiciones encontraron dos actividades que hasta entonces habían sido relegadas a los pequeños oficios del hogar, pero que en algunas oportunidades habían sido objeto de comercialización. Esos productos eran: el puro y el junco. El primero, aprovechaba los numerosos árboles de calabaza para con 
su fruto construir vasijas; el segundo, se había utilizado para construir aparejos para las bestias y esteras para dormir. Hasta entonces no se les había visto con perspectivas comerciales, pero, ante la crisis se descubrieron como ramos posibles de explotar. (Zuluaga, 1987)

El espléndido valle del Patía, se extiende enmarcado por las estribaciones de las cordilleras central y occidental, al sur del Departamento del Cauca - Colombia, el cual históricamente estuvo habitado por los indios Patías que se situaron en la parte plana del municipio, los cuales fueron exterminados totalmente en la época colonial, bajo la supremacía y dominación de los españoles.

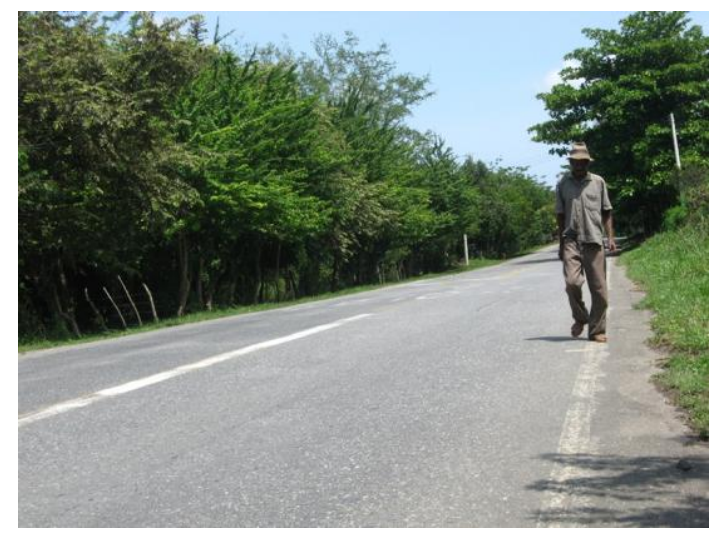

Figura 2 - Mayor de la Vereda Piedra de Moler, caminando por la vía panamericana. Municipio del Patía (CaucaColombia). Foto: Luis Antonio Rosas

La población del Patía se encuentra ubicada en la parte central de la fosa, al margen oriental de la parte plana del valle; que se caracteriza por ser bajo, plano y un tanto angosto. El río Patía pasa por la parte occidental del pueblo, pero muy distante de éste. Zuluaga, en uno de sus textos refiere el valle del Patía, así:

Atravesado por el curso medio del río Patía, este valle interandino se localiza al sur de Colombia en el espacio intercordillerano a que da lugar la bifurcación de los Andes para dar comienzo a las cordilleras central y occidental. Allí, los períodos secos y lluviosos son rigurosos y dan origen a dos paisajes que -sobre el mismo espacio- se suceden en el tiempo: uno, el del período de lluvias, muestra una región fértil, verde, 
abundante en pastos, ganados y producción agrícola; el otro, el de verano, es un valle roji-negro, aparentemente estéril, donde los ganados macilentos se alimentan de raíces de "puntero"[2] y del "puro" que -al desplomarse del árbol- rompe su corteza y brinda su carnosidad húmeda a los vacunos. (Zuluaga, 1998)

Las poblaciones se ubicaron inicialmente a orilla de los ríos Patía, Sajandí, Guachicono, algunas quebradas y zanjones que posibilitaron el cultivo de plátano, maíz y yuca fundamentalmente, además de otras formas de subsistencia que fue complementada con actividades como el mazamorreo, la caza, el pancoger y la pesca. (Bermúdez, 1996:32).

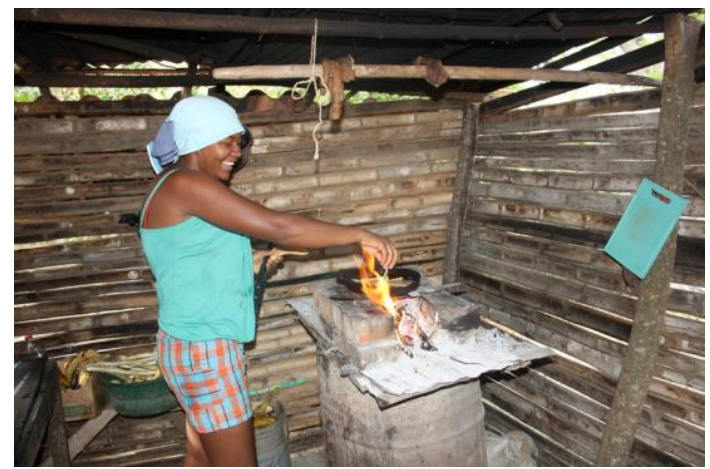

Figura 3 - Mujer cortamate de la vereda Mulalo preparando alimentos antes de la recolección de puros. Municipio del Patía (Cauca-Colombia). Foto: Luis Antonio Rosas

Con el proceso de adquisición de tierras por parte de los terratenientes, situación que llevo a la conformación de las haciendas y las minas como unidades productivas en la región, sumado a la apertura de la carretera panamericana en 1930, en el valle del Patía se desarrolló por parte de terratenientes un renglón de explotación de gran importancia, como fue la producción ganadera en las haciendas, para el caso en particular de los negros, la gran mayoría desempeñaron labores asociados a los roles de jornaleros, obreros y peones; otra gran minoría, gozaba de algunos "privilegios" por parte de sus amos, que en respuesta a su alto grado de lealtad y acatamiento de las disposiciones con sus "patronos", "compradores" o "terratenientes", desempeñaron oficios de capataces y mayordomos de las minas y las haciendas. En el caso de las mujeres negras, éstas se ocupaban generalmente de los oficios domésticos en las haciendas, pues además de garantizar la alimentación de los peones y/o esclavos negros de la mina y la hacienda, 
debían igualmente responder por los cuidados y la limpieza de la vivienda, situación que involucraba entre otros oficios lavar, limpiar, coser y cuidar los hijos de sus amos, es de anotar que en algunos casos los historiadores registraron testimonios de mujeres negras, que además de estos oficios, eran obligadas por sus amos a satisfacer sus deseos sexuales, conducta igualmente adoptada por parte de los hijos de éstos.

De otra parte, y para el caso de las mujeres negras que por razones de "compasión" o "misericordia" proferida por sus amos hacia éstas, se les permitía contraer matrimonio, las mujeres negras, además de asumir los roles domésticos que le implicaba la hacienda, debía corresponder a su marido con sus obligaciones de esposa, madre o de pareja sentimental.

Hoy por hoy, las mujeres afropatianas, conservan su rol de mujeres incansables en el desarrollo de una serie de oficios que históricamente han asumido desde la época colonial, coligados a éstos, les ha brindado la posibilidad de poder preservar algunas prácticas y tradiciones como su sustento, tanto para ellas como para sus familias.

En el caso en particular de las mujeres del valle del Patía que se ocupan del oficio de cortamates, -oficio mayoritariamente femenino-sus labores domésticas asociadas a la atención de sus hijos y de su esposo, se conjuga con su oficio de "cortamates". Es de anotar que en muchas familias, esta práctica de economía familiar mediante la recolección de los puros y su procesamiento para comercializarlos como mates, se ha constituido en una actividad sociocultural de gran importancia tanto para las mujeres afropatianas, como para sus familias, pues de acuerdo a su connotación, esta actividad implica una organización de los horarios y los roles de cada miembro del grupo familiar.

Aunque comercializar el fruto del árbol del totumo no es una actividad fácil para las mujeres y en sí para toda la comunidad patiana, el mate sigue siendo su subsistencia. Es por eso que lo usan también en otras de las diversificaciones que se le da al fruto: la de bisutería y decoración, actividades que en manos de los artesanos locales buscan, entre otras cosas, imprimir en lo creado un poco de la tierra donde son oriundos.

El oficio de cortamate es una práctica liderada generalmente por las mujeres negras del Patía, aunque en algunos de los oficios que implica la producción de mates, se involucran miembros de la familia, es la mujer que está al frente de todo el proceso desde la recolección hasta el secado de los puros, a continuación se describirán de manera sucinta cada una de las etapas por las cuales las mujeres cortamate convierten los "puros" en "mates" para su comercialización y de esta forma contar con algunos recursos económicos para su subsistencia. 
La mujer cortamate antes de salir a recolectar los puros, debe levantarse desde muy tempranas horas -tres o cuatro de la mañana- dejar preparando el desayuno para su familia, una vez realizada esta labor, procede a salir en busca de su sustento diario, es decir, los puros o frutos del totumo. Las mujeres mayores suelen transmitir su conocimiento a sus hijas y nietas, quienes inician el oficio desde el hecho mismo de recolectar los puros del árbol, por ello en algunos casos acostumbran realizar estas actividades en compañía de éstas.

Para ello, suele abrigar su cuerpo con prendas deterioradas por el uso, como camisetas y sudaderas, dispone además de unas botas entarquinadas de polvo y barro, sobre su cabeza, acostumbra disponer un lienzo o trapo enrollado, el cual lo utiliza para contrarrestar el intenso frio del amanecer en sus largas caminatas, a su vez que les sirve para mitigar sobre la misma, el considerable peso de la costalilla cargada de puros, una vez ha completado la cosecha de la jornada. La mujer cortamate lleva consigo un garabato, es decir, un largo y delgado listón de madera fina, de una longitud que oscila entre los 4 a 6 metros de altura, el cual dispone en una de sus puntas de un gancho artesanal para ensartar y desgajar con facilidad el fruto del árbol. Posteriormente caminando o a caballo procede a adentrarse en los potreros y/o fincas en las cuales se les permite acceder a cosechar los puros, en el sitio de cosecha al pie de los arbustos de totumo, la mujer cortamate procede a despulparlo, proceso que se realiza partiendo el puro en dos partes iguales, tarea que desempeña apoyada de un pequeño machete. Seguidamente procede a despulpar, término que emplean las mujeres para referirse al proceso por medio del cual se les saca las semillas contenidas en su interior al totumo, estas semillas son proporcionadas al ganado que merodea a las mujeres, que bajo los arbustos y resguardadas del intenso sol que caracteriza la región patiana, efectúan el despulpe de los frutos.

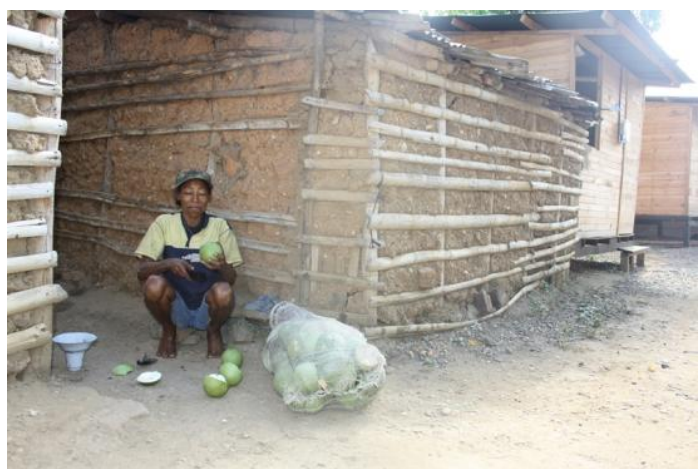

Figura 4 - Mujer cortamate de la vereda Mulalo en el proceso de corte y despulpe de los puros. Municipio del Patía (Cauca-Colombia). Foto: Luis Antonio Rosas 
Una vez despulpados los puros, éstos se depositan en las costalillas, la mujer cortamate da por terminada su jornada de recolección, cuando generalmente ha logrado apiñar entre 15 a 30 docenas de puros, luego de ello, procede a colocar esta pesada carga sobre el lomo de su cabeza, para emprender la caminata de regreso a su morada, caminatas de largas y extenuantes distancias, las cuales pueden durar entre una a tres horas, situación que las obliga organizarse en grupos de por los menos tres mujeres en adelante para salir a cosechar, debido a que entre ellas se ayudan mutuamente tanto para bajar de sus cabezas la costalilla de puros, como para subirlas a las mismas al momento que deciden tomar un descanso en su agobiante trayectoria.

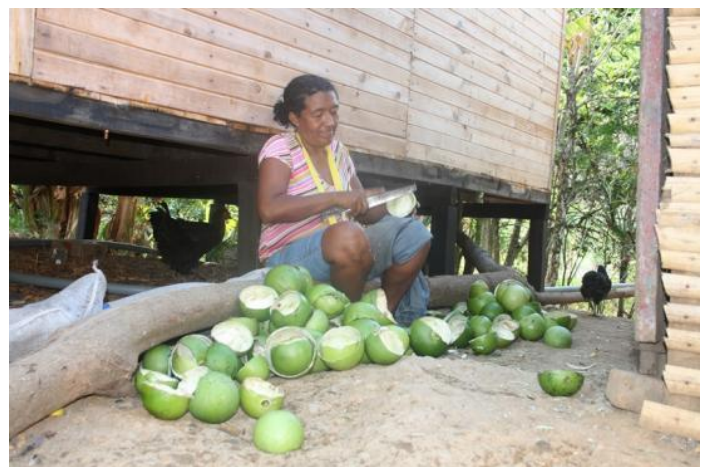

Figura 5 - Mujer cortamate de la vereda Mulalo puliendo los puros para proceder a cocinarlos. Municipio del Patía (CaucaColombia). Foto: Luis Antonio Rosas

Ya estando en su vivienda, la mujer cortamate se ocupa del aseo y organización de su casa, y mientras "colocan las ollas para el almuerzo" -como suelen referirse a la preparación de los alimentos para el almuerzo- se disponen a emparejar los puros, actividad que consiste en pulir los bordes de éstos, para ello, los apoyan uno a uno en el lomo de sus piernas, y con la ayuda de un pequeño machete debidamente afilado, proporcionan de manera diestra y cautelosa una forma regular y lisa a los bordes de los puros; para evitar cortarse sus piernas con el machete, preventivamente cubren su pierna con una frazada o pedazo de trapo, protegiendo de esta manera su integridad física.

Este oficio, de emparejar, es interferido en varias ocasiones, debido a que la mujer cortamate debe estar "inspeccionando" la cocción de los alimentos para el almuerzo y en una u otra "parada" atizar el fogón y/o adicionar algún ingrediente o condimento a la sopa y/o guiso. 
Una vez emparejados los puros, se procede a cocinarlos, este proceso se lleva a cabo con el objetivo de ablandar los residuos que quedan adheridos a las paredes de los puros, a su vez que este proceso de cocción le proporciona un blanqueamiento al puro. Para este proceso la mujer cortamate, atiza un fogón de leña, sobre el cual coloca una olla de tamaño considerable y con suficiente agua, una vez el preciado líquido ha alcanzado su punto de ebullición, la mujer cortamate vierte los puros y los deja aproximadamente media hora cocinándolos. Luego de lo cual, la mujer cortamate se dispone a rasparlos, el "raspa'o" como suelen denominarlo, consiste en retirar del puro los restos de pulpa que han quedado adheridos a la pared del puro. Para el desarrollo de esta labor, la mujer cortamate se vale de un artefacto denominado "raspador", básicamente es un pequeño machete, al cual manualmente le han proporcionado una curvatura en su punta para que se amolde apropiadamente a la forma redonda de los puros y facilitar de esta manera el raspado de los residuos de pulpa del fruto.

A la postre se prosigue con el secado de los puros para convertirlos en mates, labor que consiste en exponerlos a la intemperie para que con los efectos de la luz solar, se efectué su secado y de esta manera se culmine el proceso del producto para ser comercializados. Las mujeres afirman que cuando los puros se cortan muy "verdes", antes de exponerlos los puros al sol, éstos se deben sacar en horas de la noche al sereno para que conserve su tonalidad blanquecina, posterior a ello ya se puede proceder a solearlos. Los puros frecuentemente deben exponerse a los rayos del sol para que la humedad no los deteriore.

Los mates una vez secos, son distribuidos a los comerciantes de estos productos, personas que hacen extensos recorridos por las diversas veredas del valle del Patía, estos recorridos se valen de pequeños vehículos como motos o camionetas, los cuales se distribuyen a comerciantes que compran el producto y los llevan a distribuir a ciudades como Cali, Huila y Neiva.

Una vez relatado el proceso que implica el oficio de la mujer cortamate, es posible comprender y dimensionar la pasión que llevan dentro de sí, las mujeres cuando aluden y hacen referencia a la importancia que les representa este fruto, así mismo de su oficio aprendido desde muy temprana edad, aquel que les ha posibilitado preservar sus tradiciones, ya que la recolección incansable de estos puros, su transporte hasta las viviendas para procesarlo y darle forma a los mates, desde tempranas horas del día, se constituye en una práctica que sociocultural de gran valor para la comunidad patiana, por cuanto desde la niñez siempre se les ha inculcado a valorar y conservar este recurso vegetal promisorio. 
Con el mate la comunidad patiana ha podido conocer las bondades de la naturaleza, saber que el totumo es místico, tal como lo expresa Daner Zapata, hábil artesano del totumo: "un árbol que para nosotros es como un misterio, porque durante muchas décadas, ese ha sido el sustento de nosotros los pobres en el Patía. Y es tan fascinante porque en este tiempo pudimos encontrar otra manera de diversificarlo, de cambiarlo, transformarlo, algo muy rico para nosotros".

\section{Las mujeres afropatianas, construyendo sentido de vida}

Las mujeres afropatianas, quienes culturalmente son las quienes más permanecen en el territorio, facultadas para el desempeño de diversas actividades domésticas, pero de igual manera de poder liderar procesos comunitarios a favor de su región, conservando sus tradiciones culturales, su historia e identidad. La situación de sus hijos/as, sus experiencias personales, sus trayectorias históricas y los dilemas cotidianos que deben enfrentar en su comunidad, configuran los principales motivos de sus procesos organizativos y solidarios con las luchas de los afrocolombianos, tanto en el ámbito local y/o regional, como en relación con las dinámicas políticas de la población negra a nivel mundial. En sus propias palabras, la mujer cumple uno de los principales papeles en la formación y mantenimiento de la cultura como patrimonio de las futuras generaciones. Alaix de Valencia en uno de sus trabajos referidos al Patía, plantea sobre las mujeres afropatianas:

\footnotetext{
Las patianas han generado nuevas actitudes tanto de comportamientos con sus semejantes, como con aquellos que las ven desde afuera. Ellas se han convertido en punto de referencia tanto para sus familias como para la sociedad. Sobresalen en el papel de madres, de esposas, y en el de maestras. En suma han impulsado otras dinámicas de vida, que se hacen visibles en la escuela, en el trabajo del campo, en la participación en labores otrora exclusivas del hombre. (Alaix de Valencia, 2009).
}

No obstante, que este rol de educadoras, de lideresas, de promotoras y de gestoras, lo han venido desempeñando durante varios siglos, hoy enfrentan también el reto de rescatar para las nuevas generaciones muchos aspectos de la tradición cultural afrodescendiente que han perdido centralidad en la vida cotidiana. Dicho propósito sigue dejando a las mujeres en la visibilidad como único escenario de lo privado, aun cuando el sentido de su acción tiene un carácter político y público, este establece ciertas limitaciones y circunscribe las posibilidades de incursionar en otras esferas de la vida social y política. 


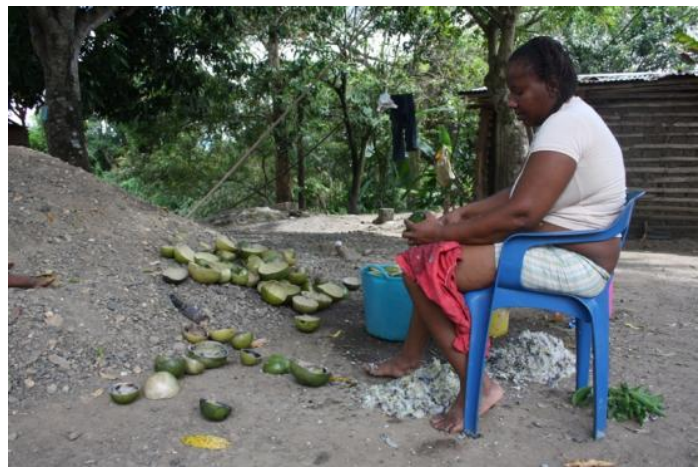

Figura 5 - Clara Velasco, mujer cortamate de la vereda Mulalo. Municipio del Patía (Cauca-Colombia). Foto: Luis A. Rosas

"La solidaridad es la única garantía que tenemos los pueblos históricamente dominados para transportarnos más allá de los límites geográficos, físicos, humanos y hasta de pensamiento que nos han impuesto a través de los tiempos" (Conferencia Nacional Afrocolombiana, 2005).

Al indagar sobre la participación de la mujer afropatiana en la vida socioeconómica de estas comunidades, aparecen relaciones de orden histórico y con una mayor inquietud por la identidad femenina en relación con otras variables identitarias, que abordan las políticas económicas y sus efectos diferenciados por sexo, la invisibilidad de las mujeres en los modelos macroeconómicos, los efectos sobre el trabajo rural y sus condiciones de vida de las mujeres, el establecimiento de políticas hacia el reconocimiento de sus conocimientos, prácticas ambientales y culturales, inserción y participación en procesos organizativos comunitarios. Trinidad et al, sostiene que:

[...] tradicionalmente, el mundo rural ha estado relacionado de manera casi exclusiva a las actividades agrarias: agricultura y ganadería, incluyendo las zonas pesqueras. La mujer ha sido un apoyo incondicional a las labores del campo, no sólo familiares, sino comunitarias, dentro de una reciprocidad o por la necesidad de ganar algún dinero"'[3].

En ese orden de ideas, sus acciones de lucha se centran fundamentalmente en la reafirmación étnica, histórica y cultural; la recuperación del territorio ancestral, la búsqueda del "etnodesarrollo"[4] como una opción que parte de las prácticas tradicionales y la participación autónoma de las comunidades negras en la toma de decisiones que las afecten. Es así más fácil entender por qué el "sufrimiento con sentido" ha llevado a las mujeres 
afrocolombianas a levantar su voz y emprender acciones comunitarias que contribuyan a obtener su reconocimiento como mujeres culturalmente diferenciadas.

Las mujeres afropatianas desde muchos años atrás han venido emprendiendo esfuerzos encaminados a resignificar no solamente sus apuestas políticas en los procesos de defensa de su territorio, sino igualmente en resignificar sus prácticas y tradiciones culturales, así mismo sus conocimientos tradicionales autóctonos, para lo cual se han visto en la obligación de organizarse como lideresas, y emprender de esta manera procesos de organización comunitaria que apunten a consolidar sus apuestas para el desarrollo de alternativas locales propias, gestadas desde las organizaciones en resistencia a la actual crisis ambiental y alimentaria que azota por la inserción de la modernidad, sumado a las políticas nacionales y departamentales que se vienen implementando en los territorios de las comunidades en el sur del Cauca que deja a las mujeres sin medios de subsistencia en la región, situación que les ha significado revindicar su papel de lucha y resistencia.

Las mujeres afropatianas a través de su organización la "Red de Mujeres Afropatianas", han establecido unos propósitos de lucha por reivindicar su rol político y cultural ante la sociedad, su condición estereotipada ante la sociedad la misma deja entrever una triple condición de ser "negra", "mujer" y "pobre" situación que la ha conllevado a su constante discriminación tan marcada por parte del sistema y la cultura, que no ofrece acceso ni garantías para alcanzar un "mejor vivir". Este escenario brinda elementos significativos para razonar desde distintas orillas compleja realidad a que se ven enfrentadas las mujeres afropatianas, pero ante todo las mujeres "cortamate", pues este oficio culturalmente e históricamente ha sido considerado dentro de la comunidad como uno de los más desvalorizados, tal como lo afirman Miryam Teresa Vidal y Diana Pito, mujeres lideresas que han acompañado el desarrollo de proyectos comunitarios a la organización comunitaria Red de Mujeres Afropatianas: "...hacia afuera esta estigmatización se ha apalancado como una de la que genera "ganancias" de quienes comercializan este producto, es mirar la "explotación" de las mujeres de su condición y no por los productos artesanales que ellas producen".

Esta realidad sociocultural con sus vicisitudes y entramado ha contribuido a subalternizar sus discursos y apuestas, su pensamiento, su cosmovisión, sus saberes y prácticas, aspectos que desde la centralidad ha hecho perder la perspectiva de analizar globalmente los fenómenos o poder interrelacionar distintos elementos de la realidad social en la que circunscriben culturalmente. Pues ellas no son ajenas a la marginalidad a la que desde remotos tiempos se han visto sometidas las poblaciones afrodescendientes, 
contrastadas por las desigualdades producto de la pobreza, el desplazamiento, relativo abandono estatal, políticas deleznables e inadecuadas, carentes de un pertinente horizonte social, económico y cultural, entre muchos otros aspectos que desfavorecen el desarrollo endógeno de las comunidades locales.

En ese sentido, la mujer afropatiana ha venido representando un papel fundamental en las dinámicas rurales agroecológicas, ya que ella asume diversas labores relacionadas con la parte agrícola que aportan a su condición socioeconómica, entre estas actividades se pueden mencionar: mejoramiento de suelos, preservación y conservación de semillas nativas, establecimiento de huertas caseras y prácticas agroecológicas, establecimiento de especies menores, producción de alimentos sanos y nutritivos, siembra y resiembra de plantas nativas, producción de plantas nativas. En tal sentido, es pertinente citar a Camacho, quien después de adelantar diversos trabajos conjuntos con grupos de mujeres e investigadoras locales en la costa chocoana, confirma:

\begin{abstract}
[...] que las mujeres tienen no solo un conocimiento amplio de su entorno, sino que juegan un papel muy importante en el mantenimiento y mejoramiento de la diversidad biológica silvestre y domesticada. Del mismo modo, corrobora el protagonismo femenino en la salud familiar y comunitaria y en la transmisión de saberes ancestrales y de la cultura a través de su participación en los ritos de paso, como la ombligada y la muerte. Plantea también que la identidad femenina está estrechamente ligada al manejo de las plantas alimenticias, medicinales, de suerte y de poder. De otra parte, resalta el intercambio y la reciprocidad como elementos centrales de las relaciones sociales, especialmente entre las mujeres, tanto en el trabajo como en las labores domésticas y la crianza. (Camacho, 2004; p. 187)
\end{abstract}

Este planteamiento deja entrever que en las prácticas de interacción con el entorno por parte de las mujeres negras en distintos espacios del territorio, se establece una división sexual del trabajo, -la topografía de género en el territorio- pero a su vez se evidencia una complementariedad entre los géneros en los ámbitos sociales y productivos.

Junto con las actividades mineras, las actividades de los afrodescendientes en la agricultura y la ganadería muestran las posibilidades que contribuyeron no sólo para producir alimentos que proveían a las explotaciones mineras, sino que además mostraron capacidades para construir economías agropecuarias capaces de dar independencia para el sustento de las familias y para establecer ciertos grados de autonomía y competencia con los mercados coloniales de los empresarios esclavistas. La Costa Caribe, el Valle del Cauca y el Valle del Patía son territorios 
ejemplares en donde se dieron estos procesos de economías agropecuarias. (Burgos, 2010; p. 144).

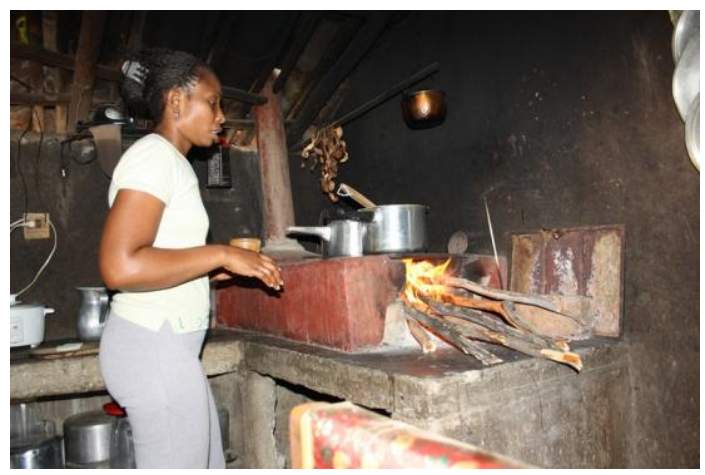

Figura 6 - Amalfi Mosquera mujer cortamate de la vereda Piedra de Moler preparando sus alimentos. Municipio del Patía (Cauca-Colombia). Foto: Luis Antonio Rosas

Otro aspecto de importancia que se resalta el papel de la mujer afropatiana hace referencia a su articulación en procesos organizativos que propendan hacia el reconocimiento y aplicación de los saberes tradicionales enmarcados en las practicas alimentarias, trabajo que últimamente se viene articulando fundamentalmente desde la perspectiva de los derechos humanos, reconociendo que la alimentación y la nutrición determinan la salud y esta a su vez el estado nutricional de las personas, las familias y la comunidad. "La alimentación no sólo es para calmar el hambre y reducir las enfermedades sino que es fundamental para garantizarle a los seres humanos condiciones físicas, mentales y sociales de bienestar que le permitan alcanzar altos niveles de escolarización, mejora la producción, favorece la equidad de género y hace posible la realización de proyectos de vida individuales y colectivos, garantía para las comunidades afropatianas a alcanzar una vida digna"[5].

En ese sentido el poder crear espacios para re-encontrarse con el pasado a través de relatos, historias de vida, vivencias y narrativas liberadoras cobra importancia para las mujeres afropatianas, en la medida que se constituye en un elemento para empoderar sus procesos organizativos, pues a través de la cotidianidad de sus vidas, "se reconoce que su legitimidad, lucha y fortaleza está en el día a día de sus aprendizajes, los recorridos por las veredas cortando mate, comprando fruta, intercambiando, apropiando, informando, socializando y compartiendo sus saberes. Lo organizativo articula a aquellas voces que históricamente han sido excluidas y acalladas por su color de piel, su etnia, sus 
orientaciones u opciones sexuales, es decir, el proceso de organización social desde las mujeres rurales es construido desde su especificidad de ser mujer y sus reivindicaciones y duras luchas en función del derecho a la tierra, la alimentación, el agua, la dignidad y el derecho a vivir la democracia el cual traduce el derecho de participar y decidir sobre el destino de sus vidas, la organización y su comunidad"[6].

Zuluaga, al respecto refiere, que:

[...] El hecho de ser estos negros en su mayoría huidos y la necesidad de unir la producción a la defensa, hicieron que se estableciera una cierta distribución sexual del trabajo donde, a la mujer le correspondieron las labores agrícolas y el mazomorreo, mientras el hombre se encargó de obtener la carne necesaria para complementar la dieta alimenticia, a través de la caza, del trabajo esporádico en las haciendas y/o el abigeato. Estas labores, que realizaba a la par con otros miembros de la comunidad, lo unían a grupos de "bandidos" que velaban por la defensa y seguridad de la familia. A esta realización del trabajo correspondió una estructura de familia, cuya estabilidad se asentó en la mujer, cabeza de una familia numerosa, construida a través del ejercicio serial de la monogamia, lo que constituyo a esta figura (la gran madre), en el punto de referencia al poder y del parentesco, dando a la sociedad un carácter matrilocalidad y de matrilinealidad social, unidas a una patrilinealidad legal y un amplio ejercicio del avunculado. Esta estructura de parentesco, unida a la forma de asentamiento en las veredas, constituidas por la concentraciones de varios platanares, generalmente en la confluencia de los ríos, creó múltiples vínculos familiares en cada vereda (y entre las diferentes veredas) haciendo que cada familia extienda su red de parentesco por la totalidad del valle, y que, en cierta forma, todos fueran parientes de todos. (Zuluaga, 1986; p. 87).

En este orden de ideas, la defensa de su territorio ha implicado un proceso de reconstrucción sociocultural de su memoria histórica como mujeres negras, circunscritas en una sociedad machista y dominante, por lo cual sus gestas están en concordancia hacia la resignificación de su papel político y cultural como mujeres afropatianas puesto que alrededor de sus prácticas locales -cortadoras de mate-, además de visibilizar por un lado, la importancia de los saberes y tradiciones ancestrales como una alternativa de resistencia a las presiones de las economías dominantes, sobresale la apuesta por hacer visible sus dinámicas organizativas y comunitarias, que mediante la Red de Mujeres Afropatianas, vienen cimentando acciones comunitarias hacia la reivindicación y reconocimiento como "mujeres negras" y en situación de un relativo proceso de "discriminación sistemática" por parte del Estado y la sociedad. 
En este sentido, el conocimiento del pasado satisface la necesidad de comprender, de dar sentido a los acontecimientos históricos, sociales, culturales que han marcado las trayectorias, experiencias y vivencias de vida de las poblaciones afrodescendientes, en este caso las mujeres negras del Valle del Patía. No en vano Todorov (1999), sostiene "que el hombre es memoria, que estamos hechos de pasado y volverlo inteligible es también tratar de conocernos mejor". De otra parte Vega, considera que:

[...] que ante un discurso histórico cada vez más científico y estructural en el que se pierden las acciones de los seres humanos, el interés por la historia escrita tiende a disminuir, pues este le ha restado a la historia esa dosis de pasión y de vitalidad que se necesita para que la gente se sienta parte del devenir histórico y no ajena al mismo. En contraposición, la historia oral reconoce la voz de aquellos que son ignorados por las historias oficiales o científicas; incorpora toda la riqueza del sentir colectivo de hombres y mujeres humildes; abre caminos para que trabajadores, campesinos, indios, negros, migrantes expresen sus inquietudes ante el pasado y el presente (Vega Cantor, 1999:25).

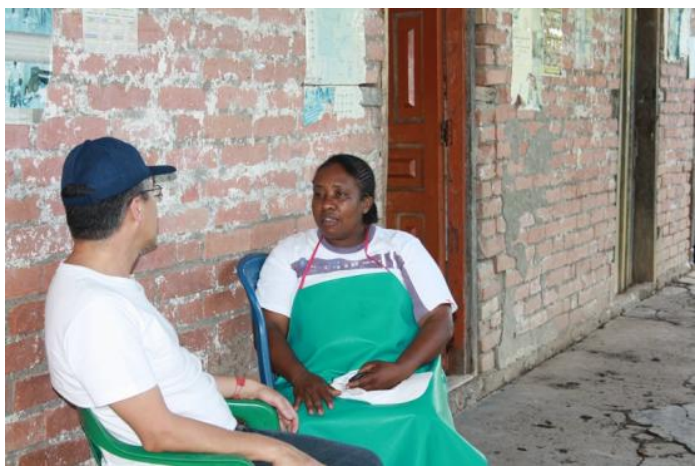

Figura 7 - María Ibarra mujer afropatiana lideresa de la vereda El Pendal. Municipio del Patía (Cauca-Colombia). Foto: Luis Antonio Rosas

Lo anterior lleva a pensar que la historia no se define únicamente a través de los acontecimientos políticos o económicos, pese a la importancia que se les ha atribuido tradicionalmente. La memoria, proyectada en el código colectivo sirve para elaborar el conjunto de mitos, lenguajes, interpretaciones, narrativas sociales vigentes, y es también, parte esencial del entramado que constituye el devenir histórico. Pensar el pasado es contarlo; recordar el pasado es obligarse a narrarlo, elaborar un relato sobre su existencia. 


\section{La formación política: una alternativa para resignificar lo femenino}

En lo que concerniente al papel político y cultural de las mujeres afropatianas alrededor de sus prácticas locales, se podría considerar que el proceso de discriminación e invisibilidad que les ha marcado durante muchos años, -fundamentalmente por parte del Estado- no son sólo obstáculos para la construcción de subjetividades políticas como podría pensarse, debido a las pocas garantías para participar y a la falta de apertura a voces distintas en la vida política, más bien favorecen el proceso ya que esas mismas condiciones denigrantes, no propias del color de la piel o del género, conducen necesariamente a experimentar eventos críticos de vida que obligan a posicionarse frente a ellos, intentando resignificarlos y resignificarse.

En un contexto de vulnerabilidad de los derechos humanos y los derechos económicos, culturales y ambientales mediado por un escenario donde se tejen las bases para un movimiento social donde se articulen procesos y se construyan alternativas de vida para la comunidad afropatiana, debe ante todo tener prioridad el resignificar la apropiación del ser como mujeres que luchan por reivindicar sus derechos desde la integralidad de los mismos, al tiempo que se establecen mecanismos de incidencia política a través del análisis e intervención de la realidad social.

Indagar sobre la forma en que las mujeres afropatianas se constituyen en "sujetas políticas" cobra gran significancia atendiendo a que ellas se vienen movilizando desde diversos contextos, en unos momentos históricos claves, amparadas en unas estrategias de interés comunitario, situación que ha conducido a resignificar y repensarse el sentido de sus gestas sociopolíticas. Pues ante ello es de considerar que las mujeres afropatianas han venido contribuyendo significativamente y desde sus particularidades, por una apuesta en materia de los derechos humanos, anteponiendo un principio esencial en los procesos de orden político el derecho a la igualdad a un trato equitativo y ante todo justo, por ello en sus apuestas renace el interés étnico, histórico y cultural, y un constante amparo por un "desarrollo endógeno" que valide y potencie las prácticas ancestrales así mismo como los niveles de participación comunitaria y soberana en las decisiones que favorezcan o afecten sus dinámicas socioculturales como poblaciones afrodescendientes.

En este sentido el papel que la mujer afropatiana viene emprendiendo desde su condición étnico/racial, permite evidenciar dos aspectos, el primero referido a la importancia que como mujeres negras -cortamate- le otorgan al reconocimiento de la diferencia, aspecto que adquiere importancia tanto desde la historia de mestizaje como en las luchas que desde tiempos remotos se han 
venido gestando, y de otra parte la importancia de la inclusión como tema fundamental del movimiento afrodescendiente, que reconoce la existencia de multiplicidad de identidades sociales en un contexto marcado por un legado histórico tan importante como lo es el Patía. Al respecto Alaix de Valencia relata, al referirse a la mujer cortamate del Patía:

La integración de la mujer al mundo público ha sido progresiva y contribuye a fortalecer el núcleo patiano; por ello, y lo reitero, siempre se encuentran alusiones a su desempeño en el trabajo tanto en la casa como en el que favorece el desarrollo económico de la región. El proceso de la cosecha, limpieza, secado y comercialización del mate es una actividad propia de las mujeres, por ello han escrito la canción Las cortamate, cuya música responde al ritmo del bambuco patiano. Cada una de las coplas nos describe cómo se lleva a cabo esta actividad y cómo ese producto vegetal de la región se elabora para convertirlo en utensilio de uso en las cocinas y para llevarlo al mercado (Cantadoras del Patía, 1997, citadas por Alaix de Valencia, 2009).

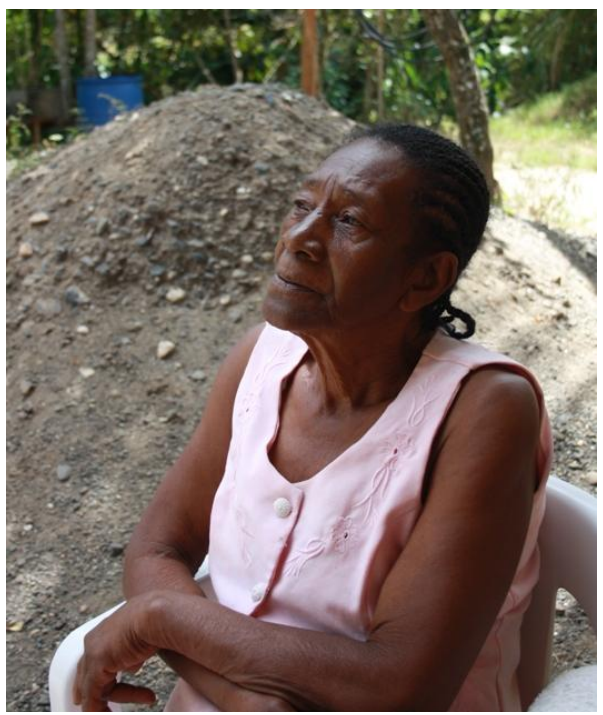

Figura 8 - Mayora Ana Celia Velasco, mujer cortamate de la vereda Mulalo. Municipio del Patía (Cauca-Colombia). Foto: Luis Antonio Rosas

Lo anterior abre un horizonte para que las mujeres negras reflexionen y reconozcan "otras-nuevas" realidades que despiertan su interés por participar en distintos escenarios, reivindicando a través de su accionar político otro tipo de derechos. Dimensiones como el género, las diferencias en la misma 
identidad afrocolombiana y la denuncia de las condiciones de discriminación, han sido común denominador en la acción pública y política de las mujeres negras, con base en sus recientes reflexiones sobre la realidad social y su toma de posición.

Tomar posición activa frente a situaciones de discriminación implica reconocerla, percibir la realidad social como dinámica y cambiante, y percibirse a sí misma como responsable de un papel activo en la historia colectiva, de asumirse como sujeto con decisión de ejercer grados de libertad y agenciamiento.

Las mujeres afropatianas, a través de una acción amplia en escenarios de participación muy diferenciados, vienen conquistando espacios de la vida cotidiana a los que la política nunca antes había entrado con fuerza. Tal vez lo más importante radica en entender que la reivindicación de intereses prácticos o estratégicos, así como la acción política tanto en la esfera pública como en la privada, se encuentran entrelazados y, en lugar de dar cuenta de un mayor o menor compromiso o de un mejor o peor liderazgo, hablan de la urgencia de crear condiciones de vida más justas y equitativas en referencia a los múltiples rostros que asume la injusticia: subordinación, discriminación, opresión y explotación.

\section{Consideraciones finales}

Aproximarse a dar significado a los hechos que circunscriben las dinámicas sociales y culturales de las comunidades afrodescendientes para comprenderlos y conocerlos mejor, permite asumir posturas epistemológicas que desde diversos ámbitos literarios, históricos, sociológicos, y que de acuerdo a su propia especificidad han aportado al conocimiento $\mathrm{y}$ entendimiento no solamente del comportamiento humano en la sociedad en la cual se desenvuelve, sino igualmente a reconocer las formas como éste se interrelaciona con el contexto cultural.

En el desarrollo de procesos organizativos comunitarios con las mujeres, se puede evidenciar un avance significativo frente a los proceso de resignificar el rol de mujer patiana, es de considerar que en un principio fue difícil romper con la cultura patriarcal donde la mujer es relegada a los oficios domésticos, se le prepara para atender al esposo, los hijos, ser madre. Situación que en diversos espacios de reflexión sobre la perspectiva de género, confundió a veces el enfoque, lo que ocasionó relaciones inequitativas entre los hombres y mujeres, ya que las mujeres tenían que realizar trabajo en el hogar y atender las actividades del proyecto, mientras sus esposos o compañeros permanecían en las casa sin hacer nada. 
En este orden de ideas, no se puede desnegar el malestar que ha embargado a las mujeres negras y precisamente ello no excluye a las mujeres afropatianas, acerca de la profunda incomodidad en los roles, actitudes y valores asignados por la milenaria cultura patriarcal, las cuales las relejaron a un lugar de sujetas subordinadas, disciplinadas y supeditadas a su condición femenina, de ser mujer [7]. Esta situación podría considerarse que está en la raíz de una rebeldía creativa, que desde el dolor encubre la negación a la que han sido objeto históricamente.

Para el caso de las mujeres afropatianas, apuestan por consolidar procesos organizativos social y cultural diferentes, donde la equidad, el respeto y valoración desde su mismidad sea mínimamente reconocido. Al mismo tiempo, la constitución de sujetas sociales -individuales y colectivos- ha tenido como condición ineludible la consolidación de una identidad de una conciencia de sí, de un sentido de sí misma con relación a las y los demás. De aquí la pregunta por la identidad femenina sea consubstancial al movimiento social de mujeres y al pensamiento feminista, a la vez, que permea las vidas personales de aquellas que se han asumido conscientemente como tales. De hecho, el activismo político de las mujeres afrodescendientes ha tenido un impacto importante en preocupaciones centrales no solo en Colombia, sino en América Latina, tales como el acceso a la vivienda, el empleo, la salud pública, la conservación ecológica, la superación de la violencia, la plena participación democrática y los derechos humanos. La importancia de la actuación de las mujeres en los procesos actuales de transformación cultural ha sido subrayada por numerosos estudios. Al respecto señala Gloria da Cunha-Gaibbai:

\footnotetext{
Por un lado, la lucha de la mujer representa una victoria sobre la modernidad patriarcal que la mantenía sometida. Por otro, puede representar el significado de la globalización, ya que la mujer de hoy puede participar más activamente en la creación de una sociedad internacional más justa (Arancibia \& Rosas 27).
}

A pesar de que las investigaciones sobre los procesos de autosostenimiento local en muchas comunidades afrodescendientes, han estado ocupadas sustancialmente de los aspectos económicos, ecológicos y programáticos, no siempre se ha logrado que estas lecturas tengan en cuenta la cosmovisión de las propias comunidades negras, es decir, sus saberes y prácticas ancestrales sobre las formas de uso, manejo y apropiación de los bienes de la naturaleza. Por tanto, resulta de gran importancia insistir en la producción de memoria colectiva, el dialogo con la tradición cultural y la divulgación de los saberes locales y prácticas ancestrales, como una alternativa de visibilización de la alteridad afrocolombiana, con sus "otros" saberes y "otras" prácticas. Lo anterior debido a que en la relación dinámica 
de las mujeres afropatianas con los procesos de apropiación de su territorio y de su identidad como mujeres negras, les permite estructurar y transmitir sus saberes y prácticas, aspecto que apunta a resignificar, discriminar y vincular diálogos de reconocimiento diferencial con "los otros" saberes y comprensiones ambientales.

Este planteamiento que conduce a repensar cómo a partir de la experiencia de lo femenino, posibilita la construcción de alternativas para la conservación de la vida y poder sentar bases para su desarrollo desde los diversos trabajos que realizan cotidianamente, desde los conocimientos y prácticas ancestrales, desde los lazos de comunidad, permitiéndoles transitar cotidianamente los espacios públicos y privados, sin separarlos, planteando alternativas de solución a los problemas propiciados por un mundo masculino afincado en la destrucción como única forma de resolver las diferencia.

\section{Notas}

[1] El totumo, Crescentia cujete L. árbol pequeño que puede alcanzar alturas aproximadas hasta de $\operatorname{los} 6 \mathrm{~m}$ de altura, normalmente ramifica a muy poca altura. Se caracteriza por sus abundantes frutos, considerados por los botánicos como bayas globosas, leñosas, pesadas que pueden alcanzar cerca de $30 \mathrm{~cm}$ de diámetro, utilizados por los pobladores del valle del Patía en la producción de artesanías, quienes afirman además que su pulpa tiene propiedades medicinales al ser cocida.

[2] Puntero: Es lina especie de pasto cuya raíz es sumamente resistente a la sequía y de rápido crecimiento con escasa lluvia.

[3] Mujer, familia y mundo rural. Dos modelos para un cambio social. Área de antropología de la escuela universitaria de trabajo social. Universidad de Alicante. (s.f.)

[4] Bonfil, (1995). Define por etnodesarrollo el ejercicio de la capacidad social de un pueblo para construir su futuro, aprovechando para ello las enseñanzas de su experiencia histórica y los recursos reales y potenciales de su cultura, de acuerdo con un proyecto que se defina según sus propios valores y aspiraciones.

[5] Apartes del documento: "Construcción de Alternativas étnico-culturales hacia la Gestión Ambiental Participativa de la Red de Mujeres Afropatianas” Red de Mujeres Afropatianas. Patía - Cauca. (s.f).

[6] Ibíd., pág. 15

[7] Junto a la cargada asignación de papeles para las mujeres reales e imaginadas que propulsaron las acciones asistenciales gravitaron con fuerza otras consideraciones de género: el papel primordial de la familia patriarcal y monogámica, las funciones paternales de provisión de la iglesia y paulatinamente del estado y los padres de familia, así como la sumisión y el control 
de quienes eran definidos como dependientes y más débiles: mujeres maltratadas, viudas, huérfanos, ancianos y lisiados.

\section{Referencias}

ALAIX de Valencia, Hortensia. Género, lengua y cultura en el entorno patiano. En: Nina S. de Friedemann: cronista de disidencias y resistencias. Arocha Jaime (Editor). Programa La Ruta del Esclavo. - UNESCO. Colección CES. Universidad Nacional de Colombia. 2009.

BATALLA, Bonfil. Obras escogidas de Guillermo Bonfil. Tomo 2. Guemes, Lina Odena (Recop.). Instituto Nacional Indigenista. México, D.E. 1995.

BERMUDEZ, Ehivar Enoc. Relaciones de intercambio en la comunidad afrocolombiana del Valle del Patía. Trabajo de Grado. Departamento de Antropología. Facultad de Ciencias Humanas y Sociales. Universidad del Cauca. 1996.

BURGOS, C., Roberto. (Editor) Rutas de Libertad. 500 años de travesía. Ministerio de Cultura. Pontifica Universidad Javeriana. Bogotá - Colombia. pp. 139-178. 2010.

CAMACHO, S. Juana. Silencios elocuentes, voces emergentes: reseña bibliográfica de los estudios sobre la mujer afrocolombiana. En: Pardo Rojas, Mauricio, et al (editor) 2004. Panorámica afrocolombiana. Estudios sociales en el Pacífico. Instituto Colombiano de Antropología e Historia. ICANH. Bogotá. Colombia. pp. 167-204. 2004.

CIEZA de León. La crónica del Perú. Madrid, Espasa Calpe. Colección Astral, Madrid. 1982

COLMENARES, Germán. La aparición de una economía política en las Indias, en Revista Universidad de Antioquia. (220). 1990.

DAVIS, Ángela Y. Mujeres, raza y clase. Ediciones Akal. Madrid. España. 2005.

LOMELI, Luis Felipe Gómez. Economía de Subsistencia y/o autonomía alimentaria. México: Nostra Eds. 2009.

LOZANO, L., Betty R. Mujeres negras (sirvientas, putas, matronas): una aproximación a la mujer negra de Colombia. Santiago de Cali. 2008.

TODOROV, Tzvetan. El jardín imperfecto. Luces y sombras del pensamiento humanista. Barcelona, Paidós, p. 319. 1999.

TORRES, José Ignacio. La comunidad negra del Patía. (Visión etnográfica) Trabajo de campo. Universidad Nacional de Colombia. Facultad de Ciencias Humanas. Departamento de Antropología. 1984.

USSA, Constanza. De los empauta'os a 1930. Popayán, Universidad del Cauca. 1989. 
VEGA, C., Renán. Disciplina histórica. Historia oral y enseñanza de la historia. En: Déjenos Hablar. Universidad Pedagógica Nacional. Bogotá. pp. 13 y 29. 1999.

ZULUAGA, Francisco. El Patía: un caso de producción de una cultura. En: La participación del negro en la formación de las sociedades Latinoamericanas. Seminario Internacional. Instituto Colombiano de Cultura, Instituto Colombiano de Antropología. Bogotá. 1986.

Humanidades, Cali, Universidad del Valle. 1993.

Los hombres históricos del Patía o los héroes del tiempo

encantado. En: Geografía Humana de Colombia: Los Afrocolombianos. Instituto Colombiano de Antropología e Historia - ICANH. 1998.

\section{Cibergrafía}

ARANCIBIA \& Rosas. Las mujeres latinoamericanas en la búsqueda de transformaciones sociopolíticas. Disponible en: http://www.bowdoin.edu/ eyepes/latam/mujeres.htm

CAROSTA, Alba. Las mujeres en el proceso independista. Disponible en: http://rebelion.org/seccion.php?id=8. 2010.

Luis Antonio Rosas Guevara

Departamento Estudios Interdisciplinarios.

Facultad de Ciencias Humanas de Sociales de la Universidad del Cauca.

Calle 5 No. 4. Popayán - Cauca - Colombia.

E-mail: luchorosas@hotmail.es / luisrosas@unicauca.edu.co

Recebido para publicação em outubro de 2012

Aprovado para publicação em dezembro de 2012 